\title{
TSUKIOKA KOGYO EN DE REVIVAL VAN HET JAPANSE NO THEATER
}

Op 3 januari 1868 kreeg Japan een nieuwe regering en werd het gezag van de Japanse keizer hersteld. Het Tokugawa shogunaat, dat ruim 250 jaar de dienst had uitgemaakt in Japan, werd in de daarop volgende zomer, na de val van Edo (nu Tokyo), afgezet en de Meiji-periode (september 1868 - juli 1912) was begonnen. Deze periode in de Japanse geschiedenis kenmerkt zich door immense maatschappelijke hervormingen en veranderingen.

Een van de hervormingen was dat de invloed van de samoeraiklasse sterk werd beperkt. Hun erfelijke inkomsten werden verlaagd en afgekocht.

Ze hadden niet langer het monopolie op geweld, en het symbool hiervan, het samoeraizwaard, verdween uit het straatbeeld. De wettelijke status als leidende klasse werd afgeschaft nu de Japanse maatschappij naar een moderne samenleving met één gelijke klasse streefde.

Echter, met de teloorgang van de heersende samoeraiklasse verdween tevens de financiële steun die deze groep de voorgaande eeuwen aan het klassieke Nô theater had gegeven. Tot die tijd was het verstilde, ingetogen, uitgebalanceerde en tevens kleurrijke Nô theater het vermaak geweest voor de krijgsadel, terwijl het gewone volk zich liet onderhouden door de meer uitbundige Kabuki voorstellingen.

Tsukioka Kôgyo, zoals hij nu als kunstenaar bekend is, werd in 1869 geboren als Hanyû (Sakamaki) Bennosuke, de tweede zoon van een herbergier in het Nihonbashi district in Edo. Tijdens zijn leven maakte hij dus de grote veranderingen mee die de Japanse samenleving onderging. Tegenwoordig is Kôgyo vooral bekend als de kunstenaar die, eind $19^{\mathrm{e}}$ en begin $20^{\mathrm{c}}$ eeuw, de voorstellingen van het Japanse Nô theater heeft vastgelegd in prenten en schilderingen.

Het Nô theater leek na 1868 aanvankelijk een stille dood te sterven, maar herstelde zich aan het eind van de $19^{c}$ eeuw toen het een nieuw publiek wist te overtuigen van zijn verstilde schoonheid. Zowel door de inspanningen van een aantal Nô acteurs, Japanse overheidsfunctionarissen, en buitenlandse bezoekers aan Japan (zoals bijvoorbeeld de Amerikaanse generaal Ulysses S. Grant [1822-1885] en de sopraan Minnie Hauk [1851-1929]), werd een revival van deze oude theatervorm ingezet. Voeg hieraan toe de belangstelling van kunstenaars zoals Tsukioka Yoshitoshi (1839-1892) en Kawanabe Kyosai (1831-1889), en de mogelijkheden die de 'gewone mensen' eindelijk kregen om deze theatervorm te leren kennen. De revival was een feit.

Kôgyo's prenten pasten in de tradities van die tijd en lieten in eerste instantie weinig van deze revival zien. Echter, al snel begon hij aan een zeer grote serie prenten met Nô en Kyôgen stukken als onderwerp (Kyôgen stukken zijn korte komische opvoeringen tussen de opvoering van gewone Nô stukken door).

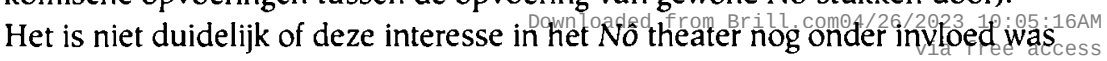


Afb. 1.

Nô maskers uit de serie Nógaku zue (Afbeeldingen van Nó stukken), circa 1900 . Collectie Koelman van Doornik, Nederland

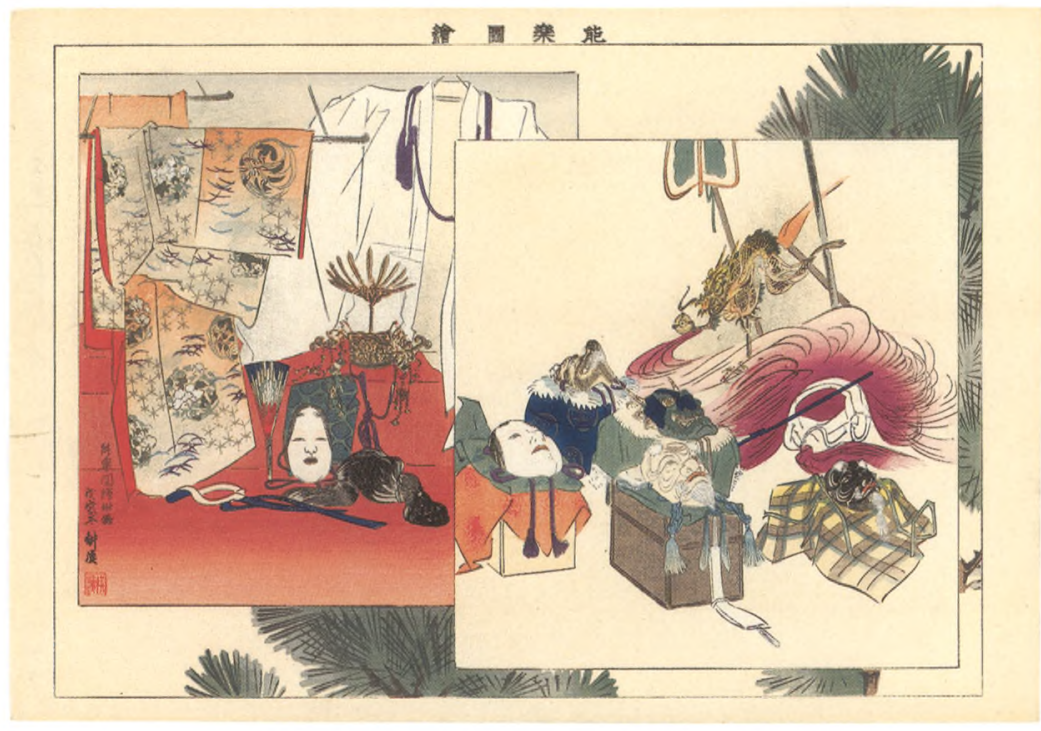

van zijn inmiddels overleden stiefvader Yoshitoshi (bij hem was hij onder andere in de leer geweest), of dat dit een commercieel initiatief was van de uitgever Matsuki Heikichi (Daikokuya). Vast staat dat de serie Nogaku zue (Afbeeldingen van Nô stukken), waarvan de eerste prenten in 1897 verschenen, met 265 prenten waarschijnlijk de grootste serie uit de Japanse prentgeschiedenis is geworden. En de herdrukken van deze prenten met een latere datum en de uitgaven in albumvorm tonen aan dat deze imposante series ook een verkoopsucces moeten zijn geweest.

De prenten geven veel informatie over de theaterstukken - vaak wordt een belangrijke scene uit het verhaal getoond - maar ook over situaties achter het toneel. Verder zijn er prenten met de zangers en muzikanten, toneelattributen en maskers, en de opbouw van het toneel zelf ( $\mathrm{afb}$. 1). Een goudmijn voor liefhebbers van deze oude theatervorm, maar ook voor liefhebbers van de drukkunst, want alle prenten in deze serie zijn bijzonder goed gedrukt met een surimono-achtige kwaliteit. ${ }^{1}$

Na deze eerste serie maakte Kôgyo nog een aantal grote series, maar zijn belangrijkste serie (zeker vanuit artistiek oogpunt) kwam tot stand tussen 1922 en 1926. Zoals voor vrijwel al zijn werk geldt, was Daikokuya weer de uitgever, maar in tegenstelling tot de Nogaku zue serie, die op een horizontaal ôban formaat (circa $38 \times 25 \mathrm{~cm}$.) werd uitgegeven, was de Nogaku hyakuban (Honderd Nô stukken) op het meer gebruikelijke staande ôban formaat gedrukt. Een tweede opvallend verschil is dat deze serie in een totaal verschillende stijl is getekend. Waar de eerste serie onder het traditionele Ukiyo-e genre valt (met eigentijdse invloeden), illustreert Kôgyo in zijn tweede grote serie de scenes in een opvallend schilderachtige stijl met duidelijke Shijô en Nihonga invloeden (afb. 2). De meeste prentverzamelaars prefereren deze serie boven de Nogaku zue serie.

In tegenstelling met het bezoek aan een Kabuki voorstelling vol actie, is het bijwonen van een Nô voorstelling voor veel toeschouwers de eerste keer een lange zit. Maar voor wie eenmaal de schoonheid en de intense spanning van deze theatervorm echt tot zich heeft laten doordringen is het een belevenis met diepgang. Ditzelfde kan gezegd worden van de vele Nón prenten die 10:05:16AM 


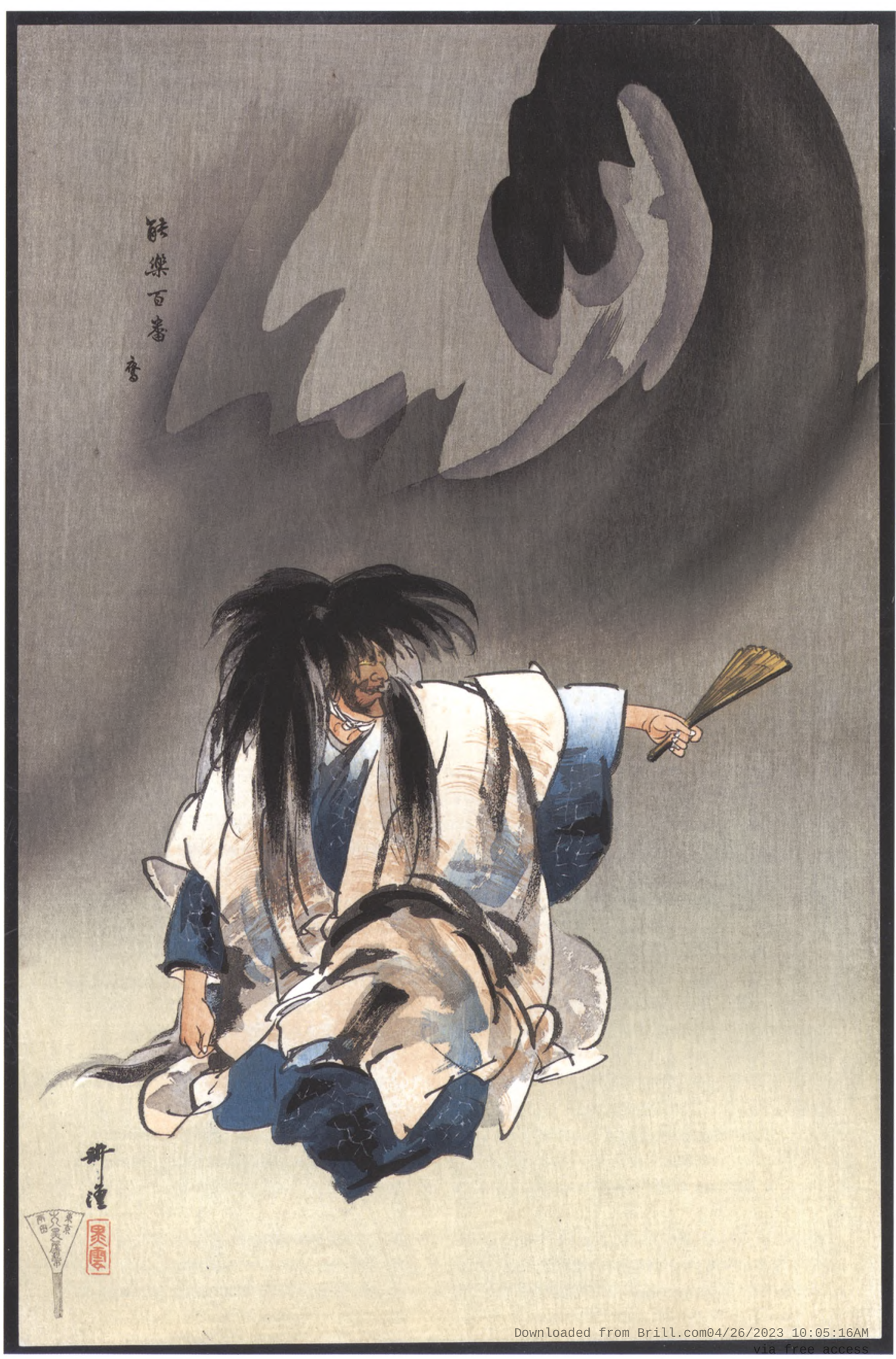


Kôgyo heeft ontworpen, voor veel beschouwers in de eerste instantie wat saai, maar bij nader inzien blijken ze zeer de moeite waard. In de geschiedenis van de Japanse prentkunst zijn er eerder kunstenaars geweest die
Afb. 2. (links)
Nue uit de serie Nógaku hyakuban (Honderd No stukken), 1925. Collectie Claus-Peter Schulz, Duitsland

prenten hebben gemaakt die direct of indirect naar het Nô theater verwezen, maar geen van Kôgyo's voorgangers heeft zijn oeuvre zo laten domineren door deze theatervorm.

Overigens heeft Kôgyo ook prentseries met andere onderwerpen gemaakt zoals landschappen. Onder deze groep vallen ook een 50 -tal prachtige natuur- en vogelprenten, ontworpen in het rond 1900 populaire shikishiban formaat (circa $210 \times 190 \mathrm{~mm}$ ). Deze prenten zijn veelal makkelijker te waarderen, maar het verdient aanbeveling om ook eens aandachtig naar zijn Nô prenten en -schilderingen te kijken, die naast hun esthetische en technische kwaliteiten een boeiend inzicht geven in de schoonheid van deze oude Japanse theatervorm.

Voor eenieder die meer over Kôgyo zou willen weten kan ik verwijzen naar mijn monografie The Beauty of Silence: Japanese Nô \& Nature prints by Tsukioka Kôgyo 1869-1927, die vorig jaar door Hotei Publishing is uitgegeven en die via diverse essays en ruim 450 kleurenafbeeldingen en appendices een verder inzicht geeft in de geschiedenis van het Nô theater in de tweede helft van de $19^{e}$ eeuw en begin $20^{e}$ eeuw en natuurlijk vooral in het opmerkelijke oeuvre van Tsukioka Kôgyo (afb. 3). ${ }^{2}$

* Robert Schaap is een verzamelaar van Japanse prenten en schilderingen, en grafisch ontwerper van veel boeken en catalogi over Japanse kunst. Hij heeft ook veel gepubliceerd op dit gebied en was ruim 25 jaar actief in het bestuur van de Society for Japanese Arts.

\section{Noten}

1. Surimono zijn prenten (vaak met gedichten erop) die privé werden uitgegeven op duur papier en met extra aandacht voor de drukkwaliteit en kleuren.

2. Schaap, Robert en J. Thomas Rimer, The Beauty of Silence: Japanese Nô \& Nature prints by Tsukioka Kôgyo 1869-1927, Leiden \& Boston, 2010.
Afb. 3.

Omslag K6gyo monografie

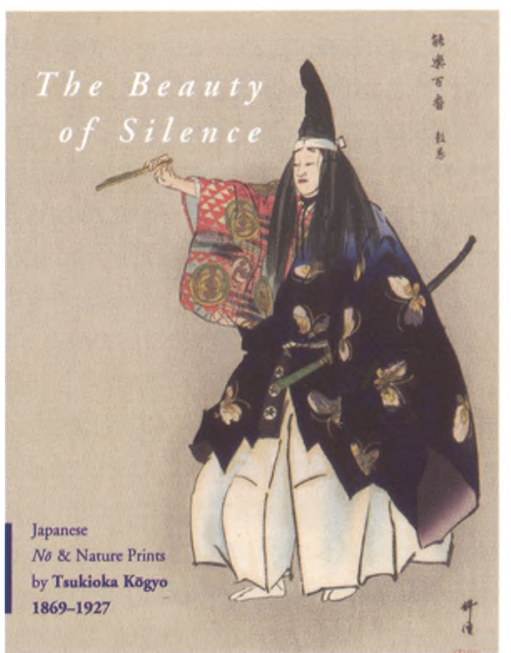

